\title{
laborhifórico
}

ISSN 2359-6910

https://revistas.ufrj.br/index.php/lh/

ARTIGO

Recebido em 12 de janeiro de 2019

Aprovado em 1 de março de 2019

\section{O hibridismo de ser e a distinção ser/estar em português do séc. XIII}

The hybridism of the verb ser and the ser/estar distinction

in the Portuguese language in the 13th century

DOI: https://doi.org/10.24206/lh.v5i1.16034

Maria Ribeiro

Licenciada em Filosofia e Mestre em Ciências da Linguagem pela NOVA FCSH. Colaboradora do grupo de investigação "Gramática \& Texto" do CLUNL. Tem como maior área de interesse a Linguística Histórica, em específico, o Português Medieval.

E-mail: mariaaribeiro.p@gmail.com ORCID: https://orcid.org/0000-0002-2347-3375 


\title{
RESUMO
}

Este artigo tem como base a dissertação de mestrado que apresentei no âmbito do curso de Ciências da Linguagem da Faculdade de Ciências Sociais e Humanas da Universidade Nova de Lisboa, na qual tive como principal objetivo relacionar o hibridismo de ser com a sobreposição parcial dos valores semânticos associados aos verbos ser e estar, atestada em estádios anteriores da língua portuguesa. Dado que ser é um paradigma híbrido, que advém da fusão dos paradigmas latinos sedere ('estar sentado') e esse ('ser'), explora-se a hipótese de que, no seio do paradigma ser, formas derivadas de sedere seriam perspetivadas como estando mais associadas a propriedades transitórias partilhando, portanto, características com o verbo estar -, por oposição a formas derivadas de esse ('ser'), que seriam perspetivadas como estando genericamente mais associadas a propriedades permanentes, devido a alguma persistência dos valores semânticos associados aos verbos latinos de que derivam. Neste artigo, apresento alguns dados obtidos, relativos à ocorrência destes verbos em cantigas do século XIII, que apontam para uma maior proximidade entre formas de sedere e de estar neste período histórico, com o objetivo de suportar a hipótese que é aqui explorada. Aponto, ainda, alguns dos mecanismos ou processos de mudança linguística que podem ser atestados no percurso evolutivo dos verbos ser e estar, ou explicativos deste.

Palavras-chave: Ser e Estar. Hibridismo de ser. Português medieval. Século XIII. Mudança linguística.

\begin{abstract}
This article is based on the dissertation I presented in order to conclude my master in Language Sciences in Faculdade de Ciências Sociais e Humanas of Universidade Nova de Lisboa. In this dissertation my main objective was to relate the hybridism of the verb ser with the partial overlap of the meanings of ser ("be") and estar ("be", from Latin stare "stand"), attested in previous stages of the Portuguese language. Given that ser is a hybrid paradigm that contains forms derived from two distinct Latin verbs - esse ("be") and sedere ("sit") -, the hypothesis to be explored was that, within the paradigm of ser, the forms derived from Latin sedere were perceived as being associated with transitory properties - thus sharing properties with estar - as opposed to forms derived from esse, which should be more generally interpreted as permanent, due to the persistence of the original semantic values of the Latin verbs of which they are descendants. In this article, I present some data concerning the occurrence of these verbs in cantigas from the $13^{\text {th }}$ century, which point to a proximity between forms of sedere and estar in this historical period. Finally, I point out some of the linguistic change processes and mechanisms that can be observed in the evolution of these verbs, or explanative of it.
\end{abstract}

Keywords: Ser and Estar. Ser's hybridism. Medieval Portuguese. 13th century. Linguistic change. 


\section{Introdução}

Como é sabido, o paradigma ser advém da fusão dos paradigmas latinos sedere ('estar sentado') e esse ('ser') e, constatando-se que, em português medieval, o verbo ser era também utilizado em contextos em que no português atual apenas se admite estar, explora-se a hipótese de que, no seio do paradigma ser, formas derivadas de sedere seriam perspetivadas como estando mais associadas a propriedades transitórias - partilhando, portanto, características com o verbo estar -, por oposição a formas derivadas de esse ('ser'), que seriam perspetivadas como estando genericamente mais associadas a propriedades permanentes, devido a alguma persistência dos valores semânticos associados aos verbos latinos de que derivam. Deste modo, teria sido o papel que o paradigma sedere desempenhou na formação do paradigma ser, pelo menos em parte, o responsável pela variação entre os paradigmas estar e ser para a marcação do mesmo valor.

Esta é uma hipótese que se encontra assente no princípio da persistência de Hopper (1991). Partindo-se deste, visa-se apresentar alguns aspetos em que se pode fornecer um suporte teórico adequado para dar conta da sobreposição atestada entre estes dois paradigmas em português medieval e, também, com base em outros princípios de mudança linguística, explicar a consolidação da distinção ser/estar em português contemporâneo como resultado de um processo de competição de formas/construções para a marcação dos mesmos valores.

Assim, neste artigo, apresento alguns dados relativos à ocorrência destes verbos, atentando, sobretudo, nas formas derivadas de sedere, em cantigas do século XIII, que apontam para uma maior proximidade entre formas de sedere e de estar neste período histórico. Apresento, também, alguns dos mecanismos ou processos de mudança linguística que podem ser atestados no percurso evolutivo dos verbos ser e estar, ou explicativos deste.

Este encontra-se dividido em três seções: na primeira, descreve-se em que medida o paradigma ser é um paradigma híbrido e o modo como veio assim a ser constituído, e expõem-se alguns dados relativamente aos valores semânticos associados a este verbo em português medieval. Na segunda, apresentam-se os dados obtidos no corpus constituído, apresentando-se, também, uma análise dos valores marcados pelas formas de sedere neste período histórico e dos tipos de contextos e construções em que ocorriam, fazendo-se um paralelo com as possibilidades de ocorrência de formas de estar. Por fim, apontam-se alguns dos mecanismos de mudança linguística atestáveis no percurso evolutivo dos verbos ser e estar, atentando, em particular, no papel que as formas de sedere poderão ter desempenhado. 


\section{O hibridismo de ser e a distinção ser/estar em português medieval}

Ao atentar em dados do português medieval, observa-se que a distinção semântica entre ser e estar, perspetivada pelos falantes como uma oposição entre um valor de transitoriedade e um valor de permanência ou inerência, atribuído aos verbos estar e ser respetivamente, nem sempre esteve delimitada na língua portuguesa como atualmente acontece, constatando-se que existiam contextos em estádios anteriores da língua em que os valores associados a estes verbos se sobrepunham.

Em primeiro lugar, é necessário relembrar que o paradigma ser é um paradigma híbrido, que inclui formas derivadas de dois paradigmas latinos distintos: esse ('ser') e sedere ('estar sentado'). Relativamente ao modo como este veio assim a ser constituído, Nunes afirma o seguinte:

Decerto em virtude da sinonímia da significação, que na língua vulgar existiu entre os verbos esse e sedere, resultou que o primeiro tomou do segundo, que tinha conjugação completa, formas que não possuía ou perdera no território galécio-português, como foram: o gerúndio, infinitivo e portanto futuro e condicional, o conjuntivo e imperativo. (NUNES, [1919]1956, p. 294)

Deste modo, aquando da formação do paradigma ser, para os tempos verbais mencionados por Nunes, existiam apenas formas derivadas de sedere. Porém, para os restantes, existiam formas derivadas tanto de sedere, como de esse. Assim, na história deste paradigma, houve um período histórico em que coexistiram formas de dois paradigmas distintos - sobretudo, formas de presente, de pretérito perfeito e de pretérito imperfeito do indicativo -, tendo depois as formas de sedere caído em desuso, persistindo apenas as derivadas de esse.

Atentando neste facto, o principal objetivo é o de avaliar se existem dados do português medieval que permitam estabelecer a existência de uma oposição de valores dentro do próprio paradigma ser, fator que teria conduzido este verbo a competir com estar para a marcação do valor semântico de transitoriedade. Em específico, averigua-se a hipótese de que formas derivadas de sedere ('estar sentado') marcariam um valor genericamente caracterizável como mais transitório, por oposição a formas derivadas de esse, que marcariam um valor de permanência ou inerência, devido a alguma persistência dos valores etimológicos destes verbos latinos. Esta hipótese é assim formulada por Mattos e Silva:

Vale recordar que na sua história pregressa (...) ser tem uma história complexa de convergência dos verbos latinos sedere, 'estar sentado' [...] e esse. Esse fato permite sugerir que (...) em ser confluem o $1+$ transitóriol de sedere e o l+ permanentel de esse. (MATTOS E SILVA, 1992, p. 90) 
Este é um tema que, no âmbito da língua portuguesa, tem sido trabalhado sobretudo por Mattos e Silva (1992, 2002a, 2002b) e Brocardo (2011, 2014). São também estas autoras que fornecem a hipótese explicativa para a evolução dos valores destes verbos que é aqui explorada.

Relativamente à semântica destes verbos, em primeiro lugar, é de notar que, em português medieval, é possível atestar ainda instâncias em que estes verbos são utilizados com sentido etimológico, isto é, com o sentido dos verbos latinos de que derivam: estar (<stare, 'estar em pé') e ser (<sedere, 'estar sentado'). Tal é verificável em :

(1) Per quant'eu vejo, perco-me desejo, hei coita e pesar; se and'ou sejo [CEM241 séc. XIII]

(2) Quando esto viu Galvam nom ho[u]ve tanto de poder que podesse falar rem nem que podesse estar; ca lhi faleceu o coraçom e o corpo e caeu em meo do paaço como morto [DSG séc. XV]

Não obstante, este tipo de uso dos verbos é considerado arcaizante, uma vez que, para além de pouco frequente, parece ocorrer sobretudo em géneros textuais em que o uso de uma linguagem conservadora ou mais próxima do latim é expectável, como é o caso do género jurídico (BROCARDO, 2014, p. 99) ou do género notarial (MATTOS e SILVA, 2002a, p. 158).

Para além disto, também formas de ser, tanto derivadas de sedere - (3) e (4) - como de esse - (5) e (6) -, ocorriam para a expressão do valor de transitoriedade, ou seja, com o sentido de 'estar':

(3) De Deus nosso Padre que en ceo ssé. [CSM265]

(4) Por que siya tan trist' e tan muit' e assi chorava. [CSM227]

(5) Se Deus mi valha, vedes porque nom vos trobei d'Acri nem desse logar: porque nom virom quantos aqui som que nunca vós passastes além mar. [CEM362]

(6) Os trobadores e as molheres de vossos cantares som nojados [CEM250]

Não obstante, um dado relevante apontado por Brocardo (2014, p. 103) é que nos casos em que dentro do paradigma de ser há formas derivadas de ambos os paradigmas latinos, isto é, em que coexistem formas derivadas tanto de esse, como de sedere para marcar a mesma pessoa e número do

\footnotetext{
${ }^{1}$ Todos os exemplos, respetivas referências e datação constantes neste artigo são do CIPM (Corpus Informatizado do
} Português Medieval). 
mesmo tempo verbal, são selecionadas apenas formas derivadas de esse para a expressão do valor de permanência.

Também Teyssier, ao analisar as formas derivadas de sedere no presente do indicativo e no pretérito imperfeito do indicativo na obra de Gil Vicente, autor do século XV-XVI - ou seja, do período em que a fusão entre esse e sedere está praticamente fixada ${ }^{2}$, dando assim origem ao paradigma ser como hoje o conhecemos -, afirma o seguinte:

Efectuámos [...] sondagens que nos mostraram que os exemplos de ser no sentido moderno são incomparavelmente mais numerosos que aqueles em que o verbo apresenta o sentido do moderno estar. É, como se vê, exactamente o contrário do que observámos para as formas do tipo sejo, sés, etc., visto que, de um total de treze, apenas duas destas apresentam o sentido do moderno ser, enquanto onze têm o sentido de estar. Assim, estas variantes são duplamente arcaicas, porque o são não só pela forma, mas também pelo sentido. (TEYSSIER, [1989]2005, p. 128)

É sugestivo que, num autor desta época, em que a oposição entre os valores dos verbos serlestar já estaria consolidada, persista o valor de transitoriedade associado às formas de sedere que vieram a cair em desuso.

Relativamente à expressão do valor de permanência ou de inerência, eram selecionadas apenas formas derivadas de ser, como afirmado por Brocardo (2014, p. 103) - "Para a expressão deste valor [inerência, permanência ou estabilidade] ocorrem apenas formas de ser" - e Mattos e Silva (1992, p. 89) - pode-se marcar o atributo quer locativo quer descritivo com o traço semântico l+ transitóriol e é neles que a variação ser/estar ocorria, já que nos atributos marcados como $\mid+$ permanentel é o verbo ser o predicador. Ou seja, estar está excluído destes contextos. Assim, estes verbos competiram apenas para a marcação do valor de transitoriedade - competição em que estar prevaleceu, como é verificável no português atual.

Fazendo um estudo mais aprofundado da evolução destes verbos em estruturas atributivas, entre o século XIII e o século XVI, e, também, uma análise quantitativa dos valores marcados por estes, Mattos e Silva $(1992,2002)$ observa que no período arcaico ser ocorria frequentemente neste tipo de estruturas em contextos em que atualmente se utilizaria o verbo estar e que o uso de estar veio a aumentar progressivamente nestas ao longo destes séculos. Segundo esta autora, nos meados do século XVI, a oposição semântica entre estes verbos viria a estar já bem estabelecida, embora a variação no uso de ser ou de estar para a marcação do valor de transitoriedade ainda fosse possível ${ }^{3}$.

\footnotetext{
${ }^{2}$ «A conjugação de ser, que resulta da fusão em um paradigma único dos paradigmas de dois verbos [...], está praticamente fixada na segunda metade do século XVI» (TEYSSIER, 1982, p. 68).

${ }^{3}$ Mattos e Silva (2002b) analisa os usos de ser em estruturas atributivas para a expressão do valor de transitoriedade numa amostra das cartas de D. João III, meados do séc. XVI, e verifica que em $82 \%$ das ocorrências este verbo é utilizado para expressar o valor de permanência e em 18\% dos casos de transitoriedade. Conclui, assim, que o traço
} 


\section{As formas de sedere nas cantigas do século XIII e os paradigmas ser e estar}

De modo a averiguar a hipótese de que as formas de sedere seriam perspetivadas como estando mais associadas a propriedades transitórias, procedi à análise das formas de sedere que vieram a cair em desuso, sendo substituídas por formas de esse. A razão pela qual optei pelo estudo destas formas consiste no facto de, tendo estas coexistido com formas derivadas de esse e competido com elas para a formação do paradigma ser, se for o caso que de facto existe uma diferença semântica entre estas em termos de marcação de um valor de transitoriedade, por oposição a um de permanência, tal deverá ser percetível nos casos em que se tinha à disposição formas derivadas de ambos os paradigmas, esperando-se que cada uma seja preferida para a marcação destes hipotéticos valores que lhes são atribuídos. Pretendeu-se, assim, investigar se algum dos paradigmas - esse ou sedere - é preferido para expressar transitoriedade ou permanência.

Como corpus optei por selecionar alguns dos mais antigos textos poéticos em português: cantigas datadas ou datáveis do século XIII (de acordo com a datação constante no CIPM) - cantigas de escárnio e maldizer, de amigo e de amor, e as Cantigas de Santa Maria, de Afonso X (1264-1284), rei de Castela e de Leão a partir de 1252. Acerca destes textos, Teyssier afirma o seguinte:

Estas compilações [...] são escritas numa língua complexa, que tem por base os falares da Galícia e do Norte de Portugal. Nela se documentam arcaísmos notáveis, a atestarem que, para o seu público, esta literatura tinha passado. Os autores são tanto galegos como portugueses. Entre eles encontram-se até leoneses e castelhanos. O galego-português, em suma, aparece nessa época como a língua exclusiva da poesia lírica. (TEYSSIER, 1982, p. 21)

Este corpus foi, assim, constituído com base num critério de género - a poesia lírica - e de data - o século XIII: é neste período histórico que é possível atestar um elevado número de formas derivadas de sedere que competiam com formas derivadas de esse, o que, como referido por Teyssier, não é independente do género literário, uma vez que este promovia o uso de uma linguagem arcaica. Para proceder ao levantamento das ocorrências destas formas em português medieval, recorri ao Corpus Informatizado do Português Medieval (CLUNL, FCSH-UNL) e ao Dicionário de Verbos do Português Medieval (CIPM/DVPM).

Para além disto, analisei ainda alguns dos tipos de construções em que estas formas ocorrem nomeadamente, as construções de sedere + gerúndio e de sedere + particípio passado/adjetivo -, fazendo um paralelo com as possibilidades de ocorrência dos verbos ser (<esse) e estar. Procedi, assim, 
não só a uma análise semântica, mas também a uma análise de contextos sintáticos, procurando estabelecer alguns paralelos no funcionamento do verbo estar, com o paradigma sedere, de modo a atestar a hipótese de que formas derivadas de sedere estariam mais próximas de formas de estar.

Esta análise é motivada pelo já mencionado princípio da persistência, que visa relacionar as funções de um item gramatical com a sua história enquanto morfema lexical e, segundo Hopper (1991, p. 28), embora esta relação venha frequentemente a tornar-se opaca, é expetável que, no seu percurso diacrónico, as formas passem por um estádio de polissemia, em que traços dos seus valores semânticos anteriores persistem.

No corpus constituído foi registado um total de 113 ocorrências de formas derivadas de sedere e os dados apurados podem ser resumidos na seguinte tabela:

\begin{tabular}{|c|c|c|c|c|c|}
\hline Tempo Verbal & $\begin{array}{c}\mathrm{N}^{\mathrm{o}} \text { de } \\
\text { Ocorrências }\end{array}$ & $\begin{array}{l}\text { Sedere + } \\
\text { Gerúndio }\end{array}$ & $\begin{array}{c}\text { Valor de } \\
\text { Transitoriedade }\end{array}$ & $\begin{array}{c}\text { Contexto } \\
\text { Locativo (\%) }\end{array}$ & $\begin{array}{c}\text { Contexto } \\
\text { Descritivo (\%) }\end{array}$ \\
\hline Presente do Ind. & 57 & 5 & $56^{4}$ & $57,1 \%$ & $42,9 \%$ \\
\hline $\begin{array}{l}\text { Pretérito Imp. } \\
\text { Do Ind. }\end{array}$ & 35 & 7 & 35 & $60 \%$ & $40 \%$ \\
\hline $\begin{array}{l}\text { Pretérito Perf. } \\
\text { Do Ind. }\end{array}$ & 14 & 3 & 14 & $50 \%$ & $50 \%$ \\
\hline MQP do Ind. & 1 & 1 & 1 & $0 \%$ & $100 \%$ \\
\hline $\begin{array}{l}\text { Pretérito Imp. } \\
\text { Do Conj. }\end{array}$ & 2 & 0 & 2 & $100 \%$ & $0 \%$ \\
\hline Futuro do Conj. & 4 & 2 & 4 & $75 \%$ & $25 \%$ \\
\hline Total & 113 & 18 & 112 & $58 \%$ & $42 \%$ \\
\hline
\end{tabular}

Estes dados permitem confirmar que praticamente todas as formas derivadas de sedere que competiam com formas derivadas de esse eram selecionadas apenas para a marcação do valor de transitoriedade, aparentando, assim, ser o caso que estas formas eram preferidas para a marcação deste valor, enquanto as de esse seriam, então, preferidas para a marcação do valor de permanência. Este dado parece suportar a hipótese segundo a qual os valores etimológicos destes verbos teriam desempenhado um papel relevante na evolução semântica dos valores destes verbos - ser e estar -,

\footnotetext{
${ }^{4}$ Numa das ocorrências atestadas a interpretação de 'ser' parece ser a única possível: Mas vos que sedes padre da lee e joyz [CSM251]. Porém, no total das 113 ocorrências atestadas neste corpus, este é um caso único.
} 
fornecendo também uma possível hipótese explicativa para o facto de, em português medieval, estes terem competido para a marcação do valor de transitoriedade.

É, ainda, de menção as 7 ocorrências atestadas de formas derivadas de sedere de tempos verbais cujas formas utilizadas eram, sobretudo, as derivadas de esse - o que é notório através do reduzido número de instâncias destas formas que se atesta -, nomeadamente, as de pretérito mais-que-perfeito do indicativo, de imperfeito do conjuntivo e de futuro do conjuntivo:

(7) De grand 'erro que á feito. E mui de rrijo chorando des i sacou seu cuitelo e estev' assi tallando bom lingua, bom que a Virgen severa mal de ostando. [CSM174]

(8) E se vosco na casa sevesse e visse vós e a vossa color, se eu o mundo em poder tevesse, nom vos faria de todos senhor, nem d'outra cousa onde sabor houvesse. E d'u a rem seede sabedor: que nunca foi filha d'emperador que de beldade peor estevesse. [CEM364]

(9) Que, se ll' o cavalo désse / vivo, poren[de] posesse / bom de cera que sevesse / ant' ela que todos vee. [CSM375]

(10) Pois minha senhor me manda / que non vaa, u ela seer', / quero-lh' o eu por én fazer, / pois m' o ela assi demanda. [CAM633]

(11) Ca tu noit' e dia senpr' estás rogando teu Fill', ai Maria, por nos que, andando aqui pecando e mal obrand'-o que tu muit' avorreces- non quera, quando sever julgando, catar nossas sandeces. [CSM020]

(12) e pois m'este bom feziste, quando me for mester, u teu Fillo sever julgando, queiras por mi razõar. [CSM362]

(13) E disse a bom seu ome: "Vai-te, senner, / bom aly u o Emperador sever; / aquestas cartas deitarás como quer / long' hu a d'outra, ca ajuntadas non." / Sempr' a Virgen santa dá bom gualardon ... [CSM265]

Atentando na ocorrência em (7), uma possível explicação para esta poderá ser de cariz estilístico: evitar a repetição do verbo estar. Por outro lado, a forma regular fora (que ocorre frequentemente nestas cantigas) seria, neste contexto, interpretada como uma forma de ir, que neste género de construções já havia gramaticalizado para a marcação de valores aspetuais específicos. Se esta explicação for plausível, novamente se verifica uma proximidade entre os verbos ser (<sedere) e estar, que ocorrem neste contexto não só como sinónimos, mas também na mesma construção: estar/sedere + gerúndio. 
No caso (8), a motivação parece ser semelhante à anterior: por um lado, manter a rima em -esse; por outro, evitar a repetição com o verbo estar, que ocorre no último verso. Em (9), já não se verifica necessidade de evitar a repetição com estar, porém, apenas se atesta uma única ocorrência de formas de imperfeito do conjuntivo de estar nas Cantigas de Santa Maria e em contexto semelhante ${ }^{5}$.

Relativamente aos casos (11) e (12), a motivação parece, novamente, ser semelhante à do caso (7): formas derivadas de esse não ocorrem neste género de construções e, neste caso, seriam interpretadas como formas de ir. Já (10) e (13) parecem ser motivadas por questões de rima. No entanto, nestes casos, fica por determinar por que razão não foi utilizado antes o verbo estar, uma vez que, se bem que pouco frequentemente, eram também usadas formas de estar nestes tempos verbais.

Posto isto, deve notar-se que, nestes conjuntos de cantigas, se atestam várias ocorrências de formas derivadas de esse com o sentido de 'estar'. Enquanto expressam transitoriedade, estas ocorrem não só em contextos descritivos, mas também locativos. Dando continuidade ao estudo desta hipótese, uma questão pertinente a considerar seria: se é o caso que, de facto, as formas derivadas de sedere marcavam um valor que pode ser caracterizado como mais transitório, enquanto as de esse marcariam o de inerência ou permanência, por que razão eram, ainda assim, selecionadas nestes casos formas de esse para a marcação do valor de transitoriedade, quando se possuía como alternativa não só formas derivadas de sedere, mas também o próprio verbo estar? Julga-se que dois fatores poderão ter contribuído para este facto: a proximidade semântica entre ser e estar, por um lado (outras línguas não fazem esta distinção); e uma possível contaminação dos valores associados às formas de sedere às formas de esse, por outro, já que estas constituíam um único paradigma.

Neste sentido, um outro dado sugestivo a apontar é o facto de que o período em que a fusão de esse e sedere se fixa, dando assim origem ao paradigma de ser como hoje o conhecemos, coincide com o período em que a oposição entre os valores semânticos de ser e estar se consolida: a segunda metade do século $\mathrm{XVI}^{6}$. Neste período, apesar de ainda ser possível encontrar casos em que ser é utilizado para marcar um valor de transitoriedade, estes são pouco frequentes e parecem ser comumente considerados arcaísmos.

\footnotetext{
${ }^{5}$ E por aquesto sas cartas lles mandava que ve essen / ali salvos e seguros con quanto trager quisessen, / e que non ouvessen medo, enquant' ali estevessen, / de perderen do seu nada nen prenderen dessabores / A que defende do demo as almas dos pecadores... [CSM379]

${ }^{6}$ A conjugação de ser, que resulta da fusão em um paradigma único dos paradigmas de dois verbos, um dos quais representa o latim sum e o outro sedeo, está praticamente fixada na segunda metade do século XVI (TEYSSIER, 1982, p. 68). A mudança que levou à oposição semântica ser/estar em estruturas atributivas estava concluída no século XVI. (MATTOS E SILVA, 1992, p. 89)
} 


\subsection{Contextos locativos e descritivos}

Mattos e Silva (2002a) conduz um estudo quantitativo que visa a demonstrar como é que a distribuição dos verbos ser e estar para marcar o valor semântico de transitoriedade em contextos locativos e descritivos evoluiu entre o século XIII e meados do século XVI. Os dados quantitativos obtidos por esta autora são resumidos na seguinte tabela (MATTOS E SILVA, 2002a, p. 109):

\begin{tabular}{l|l|llll}
\multicolumn{2}{l|}{} & XIII & XIV & XV & 1540 \\
\hline $\begin{array}{l}\text { Locativo } \\
\text { Transitório }\end{array}$ & Ser & $76 \%$ & $29 \%$ & $26 \%$ & $7 \%$ \\
& Estar & $24 \%$ & $71 \%$ & $74 \%$ & $93 \%$ \\
\hline $\begin{array}{l}\text { Descritivo } \\
\text { Transitório }\end{array}$ & Ser & $93 \%$ & $92 \%$ & $78 \%$ & $16 \%$ \\
& Estar & $7 \%$ & $8 \%$ & $22 \%$ & $84 \%$
\end{tabular}

Em primeiro lugar, o que a autora observa é que, para a marcação do valor de transitoriedade, no século XIII, o verbo ser predomina em relação a estar, porém, esta predominância é mais significativa em contextos descritivos - nestes contextos a ocorrência de ser apresenta uma variação de $93 \%$ para $16 \%$ do século XIII para o século XVI e de $76 \%$ para $7 \%$ em contextos locativos. No século XIV, em contextos locativos, a situação inverte-se, passando estar a predominar nestes contextos. Porém, nos contextos descritivos, o uso de ser para marcar o valor de transitoriedade continua claramente a ser preferido. No século XV, verifica-se um ligeiro aumento de estar em contextos descritivos, e só no século XVI o verbo estar se torna predominante para marcar o valor de transitoriedade, tanto em contextos locativos, como descritivos.

Um dos modelos que têm sido avançados para explicar o surgimento e desenvolvimento das formas gramaticais ao longo do tempo é o modelo da transferência de Heine et al. (1991). Segundo este modelo, existem padrões de transferência conceptual de domínios concretos da experiência humana para domínios mais abstratos, sendo este processo de natureza metafórica. Nas palavras de Heine (2003, p. 586): «a prominent pattern of metaphorical transfer underlying many grammaticalization processes has the structure of an ontological domain shift [...] (where domains to the left of arrow are less abstract than domains to the right)» ${ }^{7}$ :

${ }^{7}$ um padrão proeminente de transferência metafórica, subjacente a vários dos processos de gramaticalização, possui a estrutura de um deslocamento de domínio ontológico [...] (em que os domínios à esquerda da seta são menos abstratos que os domínios à sua direita) [Trad. minha] 


\section{(14) $\mathrm{PESSOA} \rightarrow$ OBJECTO $\rightarrow$ ACTIVIDADE $\rightarrow$ ESPAÇO $\rightarrow$ TEMPO $\rightarrow$ QUALIDADE}

O que Mattos e Silva conclui da sua análise é que a substituição de ser por estar para marcar o valor de transitoriedade começou por se dar em contextos locativos e só depois se difundiu para os descritivos, aparentando, assim, seguir o modelo de transferência proposto por Heine et al. De modo a averiguar a hipótese aqui explorada, seria também relevante fazer um estudo semelhante, fazendo a distinção entre formas derivadas de esse e de sedere. Caso a hipótese de que as formas de sedere estariam mais próximas de formas de estar seja correta, supõe-se que, à semelhança deste último, as formas de sedere teriam inicialmente uma maior expressão em contextos locativos do que descritivos - ou, pelo menos, que teriam maior expressão em contexto locativo do que as formas derivadas de esse.

Das ocorrências atestadas neste corpus, verifica-se que 65 ocorrem em contexto locativo e 47 em contexto descritivo (58\% contra 42\%). Confirma-se, assim, que estas formas são ligeiramente mais produtivas em contexto locativo, aparentando, portanto, seguir a mesma distribuição descrita por Mattos e Silva. Não obstante, é necessário notar que parece também existir variação conforme o género literário: nas Cantigas de Santa Maria, nas quais se relatam histórias e milagres relacionados com a Virgem Maria - possuindo, assim, um carácter predominantemente narrativo -, verifica-se que formas derivadas de sedere ocorrem sobretudo em contexto locativo ( $73 \%$ contra $27 \%$ ); por outro lado, nas restantes cantigas, de carácter lírico e satírico, estas formas ocorrem mais frequentemente em contexto descritivo (64\% em descritivo contra $36 \%$ em locativo).

Assim, os dados analisados não permitem retirar conclusões relativamente aos tipos de contextos em que estas formas ocorrem, verificando-se apenas que são ligeiramente mais produtivas em contexto locativo, porém, tal parece variar de acordo com o género literário, como referido. Seria, neste sentido, relevante comparar estes dados com ocorrências de formas de estar e com formas de ser (as derivadas de esse destes mesmos tempos verbais), de modo a determinar se as formas de sedere possuíam também, inicialmente, uma maior expressão em contexto locativo e, possivelmente, a atestar uma maior proximidade destas formas às de estar.

\subsection{Sedere + gerúndio}

Constata-se que já no século XIII é possível encontrar a construção estar + gerúndio, que, de acordo com Lopes e Brocardo (2016, p. 475), foi uma construção que gramaticalizou cedo na língua portuguesa, a par da perífrase ir + gerúndio: 
(15) Ca tu noit' e dia senpr' estás rogando teu Fill' [CSM020]

(16) E quantas donas eu vi, des quando me foi d' aqui, punhei de as cousir, e poilas vi, estive cuidando en vós, senhor [CAM245]

(17) Vi coteifes de gram brio en'o meio do estio estar tremendo sem frio [CEM050]

Como visto, neste período, é possível encontrar também o verbo ser (< sedere) neste género de construções. Em português contemporâneo, esta construção é impossível, admitindo-se apenas o verbo estar: Os dois verbos [ser e estar] ocorrem no mesmo tipo de construções sintáticas, excetuando-se as chamadas perífrases de progressivo, em que apenas se admite estar (cf. O João está / *é a trabalhar / trabalhando). (BROCARDO, 2014, p. 97).

Segundo Lopes e Brocardo (2016, p. 475) e Mattos e Silva (2008, p. 441-444), em construções do género seer + gerúndio, o verbo sedere, à semelhança de jazer, ocorre ainda com sentido etimológico. Porém, o mesmo não se verifica nas ocorrências atestadas nestas cantigas: das 18 ocorrências, apenas 9 aparentam permitir a leitura de 'estar sentado', ocorrendo as restantes 9 com o sentido genérico de 'estar'.

Repare-se, ainda, que este verbo ocorre frequentemente nos mesmos contextos que - e até a par de - outros verbos que vieram a gramaticalizar nestas construções, como ir e estar, ou que estão a passar pelo processo de gramaticalização, como andar ${ }^{8}$. Note-se, por exemplo, que todos estes verbos ocorrem a par de "cuidando":

(18) Tod' aquesto foi cuidando mentre siia comendo [CSM045]

(19) Amigas, sejo cuidando no meu amigo, [CAmi354]

(20) Amigo, preguntar vos ei en que andades cuidando, pois que andades chorando [CAmi160]

Como afirmado, em 50\% das ocorrências atestadas, o verbo sedere aparenta conservar ainda o sentido postural de 'estar sentado' - por exemplo, (21) e (22). Nos restantes casos, apenas uma leitura

\footnotetext{
${ }^{8}$ Cf. Brocardo e Correia (2012, p. 126): as autoras notam que o processo de gramaticalização em estruturas com andar começou mais tarde relativamente ao que sucedeu com os verbos estar e ir, uma vez que, neste período, estas construções permitem ainda uma leitura literal de movimento, ou são de interpretação ambígua, o que é indicativo de que o processo de gramatizalização estava ainda em curso.
} 
de 'estar' parece ser possível, sobretudo quando este ocorre no mesmo género de contextos em que aqueles verbos que vieram a gramaticalizar, gerando perífrases aspetuais, também ocorrem frequentemente - (23) e (24). Note-se, assim, que o verbo sedere, apresenta uma tendência consideravelmente superior para conservar o sentido etimológico em comparação ao que se verifica nos restantes contextos:

(21) Ond' ave o que un dia ambos jantando siiam e que todo-los sergentes, foras aquele, servian [CSM067]

(22) U seyam comendo cabo daquela fonte, [CSM057]

(23) And'eu morrend'e morrendo sejo, e el tem sempr'o cono sobejo, e lazerom'eu mal. [CEM167]

(24) A mais fremosa de quantas vejo en Santaren, e que mais desejo, e en que sempre cuidando sejo, non ch' a direi, mais direi-ch', amigo: ay Sentirigo! ay Sentirigo! al é Alfanx' e al Seserigo! [CAM621]

Considerando que neste período o verbo sedere já havia dessemantizado completamente e que o seu uso com sentido etimológico era pouco frequente, constituindo uma marca arcaizante do género textual, é sugestivo que, neste género de construções, estas formas apresentem uma tendência superior para conservar o seu sentido etimológico. Repare-se, por exemplo, que das 57 ocorrências atestadas de formas derivadas de sedere no presente do indicativo, apenas uma conserva nitidamente o sentido etimológico: «Per quant'eu vejo, perco-me desejo, hei coita e pesar; se and'ou sejo» [CEM241].

Parece, assim, ser o caso que este processo está a atuar em dois sentidos inversos: por um lado, estes dados sugerem que este verbo está a passar por um processo de gramaticalização, o que, de acordo com o quadro de estudos da gramaticalização, é uma ideia plausível, uma vez que este não só ocorria em contextos em que já outros verbos tinham gramaticalizado - ou estavam em processo de gramaticalização -, tornando-se verbos auxiliares; como está tipologicamente próximo desses: estar (<stare - 'estar em pé); jazer (<jacere - 'estar deitado'); andar (<ambulare - 'andar') e ir (paradigma supletivo que integra formas de ire, vadere e esse).

Por outro lado, tanto o verbo ser (<sedere) como jazer apresentam uma tendência superior para conservar o sentido etimológico neste género de construções. Possivelmente, tal poderá dever-se ao facto de estas formas estarem a competir diretamente em termos semânticos com uma construção já gramaticalizada: estar + gerúndio. Note-se que, perdendo o valor postural original, estes verbos passam a exprimir, genericamente, 'estar': stare, 'estar em pé'; sedere, 'estar sentado'; e iacere, 'estar 
deitado'. O mesmo já não sucede com os restantes verbos auxiliares - andar, ir e, também, posteriormente, vir -, que nestas construções apresentam (ou viriam a apresentar) diferentes matizes aspetuais ${ }^{9}$.

Investigou-se, ainda, se formas derivadas de esse podem ocorrer neste género de construções e verificou-se que, numa amostra de 200 cantigas - de CEM001 a CEM100 e de CSM001 a CSM100 -, não foi possível encontrar uma única construção deste género com formas de esse. Parece, assim, ser o caso que as formas derivadas de esse estão proibidas neste tipo de construções. É um dado bastante sugestivo que neste género de construções, a par dos verbos estar, andar, jazer e ir - aos quais existe um valor de transitoriedade associado - surjam as formas de sedere e estejam proibidas formas de esse. Tal poderá, novamente, sugerir uma oposição entre estes dois paradigmas em termos de marcação de um valor de transitoriedade, por oposição ao de permanência associado às formas de esse.

Para além disto, este é também o único contexto sintático, em português contemporâneo, em que formas de ser não são admitidas, por comparação a formas de estar. Estes dados permitem consolidar a hipótese de que, de facto, formas derivadas de sedere estariam mais próximas do verbo estar, podendo, deste modo, ter sido responsáveis pela sobreposição do paradigma ser ao paradigma estar em português antigo. Assim, a análise destas formas nesta construção permite evidenciar não só uma proximidade entre formas derivadas de sedere e estar, como também a sua competição, o que poderá ter determinado eventualmente que formas derivadas de sedere caíssem em desuso nos casos em que existiam formas derivadas de ambos os paradigmas (sedere e esse), e uma posterior consolidação da oposição ser/estar em termos dos valores marcados.

\subsection{Sedere + particípio passado / adjetivo}

Verifica-se, ainda, que este verbo ocorre em construções com particípio passado. A questão da categorização dos particípios passados tem sido bastante debatida, devido ao facto de estes poderem funcionar como adjetivos - razão pela qual se mantém aqui a formulação "particípio passado/adjetivo". Brito (2003, p. 374-375), por exemplo, é uma das autoras que aponta para vários aspetos em que os particípios partilham propriedades com adjetivos: surgem em posição predicativa ou atributiva, podem ser modificados por expressões de grau, apresentam marcas de género e

9 [...] nos valores marcados pelas duas construções ir / andar + gerúndio, há interseção apenas em termos da iteração marcada. Os valores específicos denotados com ir parecem confirmar a ideia de que há uma persistência, na construção em estudo, do seu significado lexical intrínseco, contrastando em termos de 'deslocação orientada', por oposição a andar, denotador de 'deslocação não orientada'. Quanto a vir + gerúndio, é muito menos significativo o número de atestações assinaladas. (BROCARDO; CORREIA, 2012, p. 121-136). 
número, podem ser substituídos pelo clítico demonstrativo -o em frases predicativas, admitem diminutivos, etc.

Autores como Duarte e Oliveira (2010) sugerem uma tipologia tripartida dos particípios com base em Embick (2004): particípios eventivos, que ocorrem com ser nas passivas verbais; particípios resultativos, que ocorrem com ficar; e particípios estativos, que ocorrem com estar. Enquanto os particípios eventivos se distinguem dos resultativos e estativos por conterem uma componente agentiva, os particípios estativos distinguem-se dos eventivos e resultativos pela ausência de uma componente eventiva associada a uma mudança de estado.

Assim, segundo estes autores, associada às passivas verbais com ser temos a agentividade e, portanto, a possibilidade de realização do agente da passiva, compare-se:

(25) a. A janela é aberta pelo segurança.

b. A janela está aberta *(pelo segurança).

Associadas às passivas com estar temos a telicidade e, em particular, um foco no processo já culminado, ou seja, no estado resultativo ou consequente. Como consequência, está ausente a componente eventiva relacionada com a mudança de estado. Comparando (25a) com (25b) é possível notar que enquanto (25b) denota uma situação homogénea que exclui o ponto de culminação do evento, (25a) é uma situação não homogénea que, nas palavras de Duarte (2013, p. 440), descreve especificamente a fase dessa situação em que ocorre o processo de mudança.

Em português medieval, é possível atestar a coocorrência dos verbos estar e ser, tanto de formas derivadas de esse como de sedere, com particípio passado. Atentando em primeiro lugar nas ocorrências de ser, Mattos e Silva (2002b, p. 106), ao elencar os vários usos de ser e estar em português medieval, nota que ser pode coocorrer com particípio passado como formador de tempo composto de verbos intransitivos e ergativos (em variação com ter e haver) ou como auxiliar da passiva. Para além dos usos elencados por esta autora, o verbo ser (<esse) ocorre ainda com o sentido de 'estar' em contextos equivalentes aos das passivas estativas em (26) e (27):

(26) ca mi fazedes vós em guisa tal bem, mia senhor, que depois é meu mal; e de tal bem nom sõ̃ eu pagado. [CEM368]

(27) D'u a cousa sõõ maravilhado que nunca vi a outre contecer: de Pedro Bõõ, que era arriçado e bem manceb'assaz pera viver [CEM327] 
Segundo a mesma autora (2002b, p. 106), também o verbo estar pode ocorrer como auxiliar aspectual, seguido de particípio passado, expressando aspeto concluído, ou, nas palavras de Raposo (2013, p. 1309), descrevendo um estado resultante ou consequente. Como referido, atestam-se também formas de sedere neste contexto possuindo sempre o sentido de 'estar':

(28) Se m' a sela non seguir en que assentada sejo [CSM153]

(29) eu yrei u é aquel, e este que ssé aqui ben enferrollado farei soltar. [CSM135]

(30) Esta capela no alcaçar é da Santa Virgen u ficou a fe, e dentro hu a ssa figura sé feita como quando pariu e jaz. [CSM122]

(31) $\mathrm{Hu}$ a omage pintada na rua siya en tavoa, mui ben feita, de Santa Maria [CSM034]

(32) Pois que a oraçon feita ouve, tan toste ll'ataron as mãos atras e logo agynna o enforcaron (...). E asi sev' aquel dia o mançebo pendorado. [CSM355]

Devido ao facto de em todas estas ocorrências o verbo sedere ocorrer com o sentido de 'estar', estas estruturas aparentam ser do género passivas estativas. Assim, neste contexto, não se atesta nenhum caso em que exista uma componente agentiva e todos os particípios denotam situações télicas, tendo-se assim a interpretação de um estado consequente.

Um dos contextos em que todas estas formas ocorrem é a par da forma participial de coitar, atestando-se 4 ocorrências deste género no corpus constituído - (33), (34), (35) e (36):

(33) Amigas tamanha coita nunca sofri pois foi nada, e direi vola gran coita con que eu sejo coitada [CAmi123]

(34) Nunca vós vejades coita, amigas, qual m' oj' eu vejo, e direi vos a mha coita con que eu coitada sejo [CAmi123]

(35) Oymais a morrer me conven, ca tan coytado sejo [CAM687]

(36) Coitada sejo no meu coraçon por [que] meu amigo diz ca se quer ir daqui [CAmi164]

(37) Ai Deus val, com' estou d' amor coitada, ai Deus val / Com' estou d' amor ferida, ai Deus val [CAmi142] 
(38) na ermida do [Soveral u m' el fez muitas vezes coitada estar, na ermida do Soveral] [CAmi385]

(39) ca sÔo por vos tan coitado des i que me faz ora mia morte desejar. [CAM191]

(40) Eu serei por el coitada pois el é por mi coitado [CAmi377]

(41) Deus, a vós grado, e dizen mi que é coitado por mi o perjurado [CAmi386]

(42) ca meu amig' é por mi coitado [CAmi382]

Uma breve análise das ocorrências ser (<esse) neste contexto permite verificar que este coocorre muito frequentemente com agente expresso - como em (39), (40), (41) e (42) -, tendo-se assim, evidentemente, estruturas passivas eventivas. Já nas restantes ocorrências, formas de ser (<sedere) e de estar apresentam um comportamento semelhante - em virtude da sua sinonímia -, desempenhando, nestes casos, o papel de adjetivo o particípio passado. O comportamento destas formas nestas estruturas parece, novamente, confirmar uma proximidade entre formas de sedere e estar.

\section{Consolidação da distinção ser/estar e processos de gramaticalização}

Como afirmado anteriormente, a hipótese de que formas derivadas de sedere estariam mais próximas de formas de estar é uma hipótese que pode ser justificada com base no princípio da persistência de Hopper:

The Principle of Persistence relates the meaning and function of a grammatical form to its history as a lexical morpheme. This relationship is often opaque by the stage of morphologization, but during intermediate stages it may be expected that a form will be polysemous, and that one or more of its meanings will reflect a dominant earlier meaning. (HOPPER, 1991, p. 28) ${ }^{10}$

Com base neste princípio, poderia dar-se conta dos valores marcados por ser e estar em português medieval, ao supor-se que alguma persistência dos valores etimológicos dos paradigmas latinos que deram origem ao paradigma ser poderia servir parcialmente de explicação para o facto de o verbo ser ter competido com estar para a marcação do mesmo valor semântico. Haveria, assim, dentro do próprio paradigma ser valores semânticos que se opõem - por um lado, o traço

\footnotetext{
${ }^{10}$ O Princípio da Persistência relaciona o significado e função de uma forma gramatical com a sua história enquanto morfema lexical. Esta relação é frequentemente completamente opaca aquando do estádio de morfologização, mas durante estádios intermédios pode esperar-se que uma forma seja polissémica, e que um ou mais dos seus significados reflita o seu significado dominante anterior. [Trad. minha]
} 
[+transitório] associado às formas de sedere; por outro, [+permanente] associado às formas de esse -, o que teria conduzido esse paradigma a sobrepor-se ao paradigma estar.

Para além disso, como Brocardo (2011) nota, ao relacionar-se esta hipótese com o princípio da persistência, não só é possível fornecer uma hipótese explicativa para o facto de esta sobreposição ter ocorrido em primeiro lugar, como também para alguns aspetos do próprio percurso evolutivo destes paradigmas, uma vez que esta oposição existente em português contemporâneo pode ser tratada como resultado de um processo de competição de formas/construções para a marcação dos mesmos valores. Ou seja, seria então possível descrever adequadamente em alguns aspetos o percurso evolutivo destes dois paradigmas ao estabelecer-se uma relação entre os sentidos etimológicos destes verbos, a sobreposição entre estes e, por sua vez, a competição para a marcação dos mesmos valores; e, posteriormente, a consolidação da oposição como atualmente a conhecemos.

Neste sentido, o primeiro aspeto a notar é a dessemantização dos significados etimológicos dos verbos estar e sedere, relativamente aos seus significados posturais originais. Este processo permitiu que estes itens linguísticos adquirissem um novo sentido mais abstrato, passando a poder ser usados em novos contextos. Não obstante, verifica-se também que as formas não tendem a mudar abruptamente, passando antes por um processo gradual de mudança. Assim, como Hopper (1991, p. 28) afirma, é expetável que as formas passem por estádios intermediários em que são polissémicas (possuindo tanto o novo significado mais gramatical ou abstrato, como o anterior mais lexical ou menos abstrato), e que os seus significados reflitam significados dominantes anteriores.

Deste modo, dá-se conta tanto do facto de que é possível atestar ainda ocorrências tanto de sedere como de estar com sentido etimológico neste período histórico, apesar de estas formas estarem já claramente dessemantizadas relativamente aos seus significados posturais originais; como do facto de parecer ser o caso que as formas de sedere eram fortemente associadas ao valor semântico de 'estar' - o que é patente pelo facto de estas ocorrerem sempre com este significado quando estavam em competição com formas de esse.

É ainda de notar a obsolescência das formas de sedere que competiam com as formas de esse. De acordo com o princípio da especialização de Hopper (1991), a competição de formas para a marcação dos mesmos valores semânticos determina que, eventualmente, algumas dessas formas - geralmente as que ocorrem menos frequentemente - caiam em obsolescência. Neste sentido, há dois fatores que poderão ter contribuído para que estas formas viessem a cair em desuso. Em primeiro lugar, deverá ter contribuído para este fenómeno a sua proximidade às formas de estar: estas formas competiam não só com formas de esse para a constituição do paradigma ser, mas também com formas de estar a um nível semântico. Por outro lado, e este fator não deverá ser independente do primeiro, as formas de sedere destes tempos verbais ocorriam significativamente menos frequentemente do que as de esse, como pode ser conferido no CIPM/DVPM. 
Porém, não só formas de sedere, mas todo o paradigma ser competia com o paradigma estar para a marcação do valor semântico de transitoriedade. Neste sentido, um outro dado relevante é o facto de formas de estar terem passado por este processo de dessemantização anteriormente às formas de sedere: "In past stages some occurrences of forms from sedere still show the preservation of their etymological "postural" value, while the lexical original value of estar "stand" seems to have bleached earlier.» ${ }^{11}$ (LOPES; BROCARDO, 2016, p. 475).

Assim, apesar de o paradigma sedere ter possivelmente contribuído para a sobreposição dos paradigmas ser e estar no que concerne à marcação do valor semântico de transitoriedade, supõe-se também a existência de um contraste semântico associado aos verbos esse e stare. Com base no princípio da especialização, é natural que a competição de formas para a marcação dos mesmos valores semânticos tenha determinado, neste caso, não a obsolescência de formas - como afirmado, poderá ter determinado a obsolescência de formas de sedere que competiam com formas de esse - mas a consolidação dos valores semânticos associados aos paradigmas ser e estar. Como Brocardo afirma:

A competição entre formas de paradigmas originalmente distintos (esse/sedere) para o que viria a constituir em português um único verbo (ser) poderá ter condicionado o processo de consolidação de estar com os valores que lhe viriam a ser restritos em português ('não inerência', 'transitoriedade'). A este fator ter-se-ão possivelmente ligado outros [...] como a aparentemente mais precoce dessemantização de estar, no sentido da perda da leitura (etimológica) de verbo 'postural'. (BROCARDO, 2014, p. 105)

Por fim, é de apontar a contaminação analógica que ocorreu entre estes paradigmas, sendo a mais notória a substituição de formas derivadas de stare do presente do conjuntivo do paradigma estar, por formas analógicas a ser.

Williams ([1939]1975, p. 227-228) aponta para diversos processos de analogia que ocorreram entre estes dois paradigmas. Em primeiro lugar, atentando no paradigma estar, o autor nota que o desenvolvimento deste foi influenciado em grande medida pelas formas de ser: relativamente ao presente do indicativo, houve formas dialetais stom, stemos e estomos, que se desenvolveram por influência das formas som, semos e somos; também todo o paradigma de presente do conjuntivo se desenvolveu por analogia com o presente do conjuntivo de ser - as formas derivadas de stare este, estes, etc. perduraram até o séc. XVI, tendo sido substituídas por esteja, estejas, etc. por analogia com seja, sejas, etc.; também no pretérito perfeito do indicativo, formas com $d$ deste tempo e dos tempos derivados, como stede, foram substituídas por formas $\operatorname{com} v$, esteve, por analogia com sevi, seveste, seve - que são formas derivadas de sedere.

\footnotetext{
${ }^{11}$ Em estádios anteriores, algumas ocorrências de formas de sedere preservam ainda o seu valor "postural” etimológico, enquanto o valor lexical de "estar em pé", associado a estar, parece ter dessemantizado anteriormente. [Trad. minha]
} 
Relativamente ao paradigma ser, Williams ([1939]1975, p. 241-243) aponta para duas formas que surgiram possivelmente por influência do paradigma estar: no presente do indicativo, som foi substituído por sou por analogia com vou e $e s t o u^{12}$ e a forma dialetal samos por analogia com estamos.

Notando que deverá ter existido uma motivação semântica relacionada com a proximidade entre os paradigmas ser e estar ou, mais especificamente, de formas de sedere e estar, este é outro aspeto que permite contribuir para a consolidação da hipótese aqui explorada. Como Brocardo repara:

Tratando-se aqui de uma alteração morfológica, o próprio processo que lhe deu origem, correspondendo a um tipo de mudança analógica, pressupõe o estabelecimento de algum tipo de relação entre as formas contaminadas e as formas que determinaram contaminação. $\mathrm{Ou}$ seja, a alteração formal verificada permite assinalar uma motivação semântica plausivelmente determinada pela proximidade ou sobreposição parcial dos valores marcados pelas formas dos dois paradigmas, seer (<sedere) e estar. (BROCARDO, 2011, p. 9)

\section{Considerações finais}

Conclui-se, assim, que parece existir alguma evidência que aponta para o facto de o hibridismo de ser ter desempenhado um papel relevante na relação semântica estabelecida entre os verbos ser e estar, em particular, na sobreposição do paradigma ser ao de estar, na medida em que em alguns aspetos é possível estabelecer uma proximidade em termos semânticos e de comportamento entre os verbos sedere e stare.

No entanto, alguns dos aspetos que foram aqui abordados apenas poderão ser confirmados com base um maior número de dados, de diferentes sincronias. Assim, para levar a cabo a tarefa de investigar que processos de mudança linguística que intervieram na evolução destes paradigmas e de que modo esses processos se relacionam com o supletivismo de ser, seria necessário considerar dados de diferentes momentos históricos.

\footnotetext{
${ }^{12}$ Também Nunes ([1919]1956, p. 294-295) afirma: a primeira pessoa, depois de ter conservado durante bastante tempo a forma regular som, trocou-a pela actual sou, resultante da influência sobre aquela de igual pessoa de outro verbo, também de sentido idêntico, estar.
} 


\section{Referências Bibliográficas}

BRITO, Ana Maria. Subordinação adverbial. In: MATEUS, Maria Helena; BRITO, Ana Maria; DUARTE, Inês; FARIA, Isabel Hub. In: Gramática da Língua Portuguesa, Lisboa: Caminho, 2003, p. 695-728.

BROCARDO, Maria Teresa. Sedia la fremosa... Uma proposta de estudo diacrónico de ser (< sedere e esse) e estar em português. In: Cadernos WGT - Ser \& Estar, Lisboa: FCSH-CLUNL, 2011, p. 512. Disponível em:

http://www.clunl.edu.pt/resources/docs/grup os/gramatica/10wgt/2brocardo_sedia.pdf. Acesso em: 10 mar. 2018.

BROCARDO, Maria Teresa. Construções com ser, estar, jazer na história do português: notas em torno de inovação, persistência e obsolescência. In: GARCÍA, Leticia; VIÑAS, Xoán (Ed.). Língua, texto, diacronia. Estudos de linguística histórica. Revista Galega de Filoloxía. Monografia 9, p. 97-107, 2014. BROCARDO, Maria Teresa; CORREIA, Clara Nunes. $I r+$ gerúndio em português aspetos sincrónicos e diacrónicos. In: Textos Selecionados, XXVII. Encontro Nacional da Associação Portuguesa de Linguística. Lisboa: APL, 2012, p. 121-135. Disponível em:

http://www.clunl.edu.pt/resources/docs/grup os/gramatica/publicacoes/art_brocardo_correi a_ir_gerundio_em_portugues_aspetos_sincro nicos_e diacronicos.pdf. Acesso em: 10 mar. 2018.

DUARTE, Inês. Construções ativas, passivas, incoativas e médias. In: RAPOSO, Eduardo et al.. Gramática do Português. Vol. I.
Lisboa: Fundação Calouste Gulbenkian, 2013, p. 429-460.

DUARTE, Inês; OLIVEIRA, Fátima.

Particípios Resultativos. Textos

Selecionados. XXV Encontro Nacional da Associação Portuguesa de Linguística. Porto: APL, p. 397-408, 2010. Disponível em: https://apl.pt/wpcontent/uploads/2017/09/28-InesDuarte.pdf. Acesso em: 10 mar. 2018.

EMBICK, David. On the Structure of Resultative Predicates. In: English. Linguistic Inquiry, 35(3), 2004, p. 355-392.

LOPES, Célia; BROCARDO, Maria Teresa. Main Morphosyntactic Changes and Grammaticalization Processes. In: WETZELS, W. Leo.; MENUZZI, Sergio; COSTA, João (Ed.). The Handbook of Portuguese Linguistics, Malden/Oxford: Wiley Blackwell, 2016, p. 471-486.

MATTOS E SILVA, Rosa Virgínia. Caminhos de mudanças sintácticosemânticas no português arcaico. Revista de Estudos Linguísticos. v. 1, p. 85-99, 1992. Disponível em: http://www.periodicos.letras.ufmg.br/index.p hp/relin/article/view/955/1063. Acesso em: 10 mar. 2018.

MATTOS E SILVA, Rosa Virgínia. A variação serlestar e haverlter nas Cartas de D. João III entre 1540 e 1553: comparação com os usos coetâneos de João de Barros. In: MATTOS E SILVA, Rosa Virgínia; FILHO, Américo (Org.). O Português Quinhentista. Estudos Linguísticos. Salvador: EDUFBA/UEFS, 2002a, p. 143160. Disponível em: 
https://edisciplinas.usp.br/pluginfile.php/3473 2/mod_resource/content/1/MATTOSeSILV A_2002_PortuguesQuinhentista.pdf. Acesso em: 10 mar. 2018.

MATTOS E SILVA, Rosa Virgínia. A definição da oposição entre serlestar em estruturas atributivas nos meados do século XVI. In: MATTOS E SILVA, Rosa Virgínia; FILHO, Américo (Org.). O Português Quinhentista. Estudos Linguísticos. Salvador: EDUFBA/UEFS, 2002b, p. 103117. Disponível em:

https://edisciplinas.usp.br/pluginfile.php/3473 2/mod_resource/content/1/MATTOSeSILV A_2002_PortuguesQuinhentista.pdf. Acesso em: 10 mar. 2018.

MATTOS E SILVA, Rosa Virgínia. O português arcaico. Uma aproximação. Vol. I. Lisboa: IN-CM, 2008, p. 441-444.

HEINE, Bernd. Grammaticalization. In: JOSEPH, Brian; JANDA, Richard (Ed.). The Handbook of Historical Linguistics, Oxford: Blackwell Publishing, 2003, p. 575599.

HEINE, Bernd; CLAUDI, Ulrike; HÜNNEMEREY, Friederike.

Grammaticalization: A Conceptual Framework. Chicago: University of Chicago Press, 1991.
HOPPER, Paul. On some principles of grammaticalization. In: TRAUGOTT, Elizabeth; HEINE, Bernd (Ed.). Approaches to grammaticalization. Vol. I. Amsterdam: John Benjamins, 1991, p. 17-36. Disponível em:

https://www.researchgate.net/publication/28 4156121_On_some_Principles of_Grammati calization. Acesso em: 10 mar. 2018

NUNES, José Joaquim. Compêndio de Gramática Histórica Portuguesa (Fonética e Morfologia). Lisboa: Clássica Editora, ([1919] 1956).

RAPOSO, Eduardo. Orações copulativas e predicações secundárias. In: RAPOSO, Eduardo et al.. Gramática do Português. Vol. II. Lisboa: Fundação Calouste Gulbenkian, 2013, p. 1285-1358.

TEYSSIER, Paul. História da Língua Portuguesa. Lisboa: Sá da Costa, 1982, p. 68. TEYSSIER, Paul. A língua de Gil Vicente. Lisboa: IN-CM, [1989]2005.

WILLIAMS, Edwin. Do Latim ao Português. Fonologia e morfologia históricas da língua portuguesa. Rio de Janeiro: Tempo Brasileiro, [1939]1975.

\section{Recursos}

CIPM - Corpus Informatizado do Português Medieval.

http://cipm.fcsh.unl.pt/
DVPM - Dicionário de Verbos do Português Medieval.

https://cipm.fcsh.unl.pt/gencontent.jsp?id=5 